\title{
Diatomeas de la Formación Río Turbio (Eoceno medio), sudoeste de Santa Cruz, Argentina
}

\section{S. GONZÁLEZ ESTEBENET1,2 y M. E. RODRIGUEZ RAISING1,3}

Las diatomeas paleógenas son escasamente conocidas en Argentina. En esta contribución se presentan los resultados de los primeros estudios realizados en la Cuenca Austral dentro de un proyecto interdisciplinario. Hasta el momento se analizaron tres muestras del Miembro Superior de la Formación Río Turbio que aflora en una localidad cercana a la ciudad homónima $\left(51^{\circ} 31^{\prime} 13^{\prime \prime} \mathrm{S}, 72^{\circ} 15^{\prime} 11^{\prime \prime} \mathrm{O}\right)$. El análisis de facies sugiere condiciones marinas someras de un ambiente posiblemente estuárico hacia la base de la sección cuya muestra contiene exclusivamente Cyclotella spp., característica de aguas salobres. La baja diversidad podría vincularse con condiciones de alto estrés ambiental. Hacia la parte media se observa una paulatina profundización en facies pelíticas con abundante materia orgánica con una alta diversidad de dinoflagelados. La presencia del bivalvo Panopea sp. en posición de vida en areniscas intercaladas entre las pelitas sugiere condiciones marinas. La muestra proveniente de esta asociación de facies está dominada por Cyclotella spp. y una flora acompañante integrada por Cocconeis cf. placentula Ehrenberg, Planothidium cf. delicatulum (Kütz.) Round et Bukhtiyarova, Gomphonema sp., Navicula sp. y Achnanthes cf. hungarica (Grunow) Grunow. Por encima se observan asociaciones de facies asignadas a canales de marea portadoras de diatomeas altamente fragmentadas que sugieren un ambiente de alta energía. El tamaño de las diatomeas halladas en las tres muestras es muy pequeño, lo que podría vincularse a aguas con baja disponibilidad de nutrientes o condiciones de estrés ambiental (poca iluminación por aguas con abundante materia orgánica y poco oxígeno).

1 Consejo Nacional de Investigaciones Científicas y Técnicas (CONICET).

2 Instituto Geológico del Sur (INGEOSUR-CCT Bahía Blanca-CONICET), Departamento de Geología, San Juan 670, (B8000ICN) Bahía Blanca, Argentina. solge3@hotmail.com

3 Facultad de Ciencias Exactas y Naturales, Universidad Nacional de La Pampa, Uruguay 151, Santa Rosa, La Pampa, Argentina. $\underline{\text { martin_rodriguezraising@yahoo.com.ar }}$ 